\title{
Calibration of restitution coefficients using rockfall simulations based on 3D photogrammetry model: a case study
}

\author{
Dong Hyun Kim ${ }^{1}$, Ivan Gratchev ${ }^{2}$, Jeroen Berends ${ }^{3}$, Arumugam Balasubramaniam ${ }^{4}$ \\ ${ }^{1,2,4}$ School of Engineering Griffith University Gold Coast, QLD, Australia, \\ ${ }^{3}$ Principal, Geoinventions Consulting Services Pty Ltd, 88 Brandl Street QLD 4113 Australia
}

Corresponding author: Dong Hyun Kim (donghyun.kim@griffithuni.edu.au)

\begin{abstract}
This paper presents a case study of an excavated rock slope to assess the coefficients of restitution using the results from field rockfall tests and corresponding rockfall simulations based on 3D photogrammetric slope surface models.

The results from the field rockfall tests showed that rockfall trajectories were controlled by the orientations of joints at the initial point of the rockfalls. The lateral dispersion ratio $\left(\mathrm{D}_{\mathrm{H}} / \mathrm{L}\right)$ of the trajectories was influenced by the shape index $(\gamma)$ of falling rocks as well. The directions of rockfall trajectories, which were obtained from the $3 \mathrm{D}$ simulation based on the $3 \mathrm{D}$ photogrammetric surface models, were in agreement with the field rockfall tests. Throughout 2D analysis, which was performed using predefined trajectories from the 3D simulations, the coefficients of restitution were successfully calibrated using elapsed times and distances obtained from the field rockfall tests.

Based on the accurate 3D photogrammetric slope model, the back-calculated coefficients of restitution from the 3D and 2D simulations combined with field rockfall tests provided consistent results between the numerical analyses and the field experimental data.
\end{abstract}

Keywords: Rockfall simulation, Restitution coefficient, Photogrammetry, Rock shape index 


\section{Introduction}

Rockfall hazards have been generally quantified using two (2D) and three (3D) dimensional rockfall simulations based on in situ rockfall experiments. Traditionally, 2D analyses were used successfully for rock slopes by many researchers (Pfeiffer et al., 1989; Azzoni et al., 1995; Stevens, 1998). However, this approach works well only in cases where the computed sections are a representative of the rockfall trajectories. This is due to the actual path of rockfall being varied depending on the shape of the falling body and topography of slopes.

Thus, the use of 3D rockfall simulations, such as CRSP (Pfeiffer, 1989; Andrew et al., 2012), STONE (Guzzetti et al., 2002), RAMMS: Rockfall (Christen et al., 2010) and Trajec3D (Basson, 2012) can overcome the limitations of 2D simulations by allowing the rock blocks to move on three dimensional surfaces. The 3D analysis require accurate topography of slope surfaces. Recent field survey data, remote sensing techniques such as LIDAR (Light Detection and Ranging), photogrammetry and TLS (Terrestrial Laser Scanning) are used to provide 3D slope models for the rockfall simulations (Dorren et al., 2006; Giacomini et al., 2012; Harami et al., 2013; Giovanni et al., 2014).

Throughout the rockfall simulations, the most important parameter for reliable prediction of rockfalls is the coefficient of restitution, which controls the trajectories of the rock blocks. In general, there are two approaches to assess the parameter: by back analysis of field tests (Azzoni et al., 1995; Agliardi et al., 2003) or by calculation through laboratory tests (Chau et al., 2002; Buzzi et al., 2012; Asteriou et al., 2012). In fact, laboratory tests have limitations such as varying in scale effects and different material types (Chau et al., 2002; Buzzi et al., 2012). Furthermore, even though back analysis is based on field rockfall tests which can lead to better predictions to obtain practical values of the coefficients for the slope materials, an investigation using many high speed cameras and heavy rock samples can make it difficult to conduct tests in the field due to the high costs of equipment.

This paper presents a case study to obtain the coefficients of restitutions through a combined method with field rockfall tests and a photogrammetric 3D surface model. The performed simple field tests could be used as reliable guidelines for predicting rockfall trajectories as well as obtaining practical coefficients of restitutions. Then, the rockfall behavior and the coefficients for the slope material are back-calculated by means of simulations based on accurate 3D rock slope models. This combined method is feasible when establishing methods for mitigation of rockfall hazards. 
Field rockfall tests using ten collected rocks from the site were performed at an excavated rock slope. Trajectory and elapsed time of each rockfall event were obtained by analyzing the results from video recordings using a normal HD video camera. To assess the coefficient of normal restitution and friction angle, Schmidt hammer tests and roughness profile measurements were carried out on the slope. A photogrammetry survey was carried out to create $3 \mathrm{D}$ surface models and 3D, $2 \mathrm{D}$ rockfall simulations were performed based on the 3D slope surface models. Rockfall trajectories were produced to reflect the shape of the slope surface. The coefficients of restitution of the rock material were then back-calibrated by parametric rockfall simulations, comparing them with the field data.

\section{Field experiments}

\subsection{Geology of the area}

The study area is an excavated slope located in Brisbane, Australia. The study slope is up to approximately 20 meters in height and $120 \mathrm{~m}$ in length and the slope is prepared for the installation of a drapery system for rockfall protection (Fig. 1). The slope comprises weathered metasiltstone and metasandstone from the Neranleigh-Fernvale beds (Willmott, 2010). The weathered rock can range from a moderately to slightly weathered grade, based on Schmidt hammer rebounds according to the weathering classification system suggested by Arikan et al.,(2007).

To identify dynamic and strength properties of the slope materials, Schmidt hammer tests were performed to the discontinuity surface of the slope and collected rock samples. The results of 40 Schmidt hammer blows for both the field tests and the laboratory tests are shown in Table 1. It has been reported that the Schmidt number of the slope materials showed a good relation with the coefficient of normal restitution $\left(R_{n}\right)$ (Peng, 2000). In general, the $R_{n}$ is an important dynamic parameter of slope material for rockfall simulation and is defined as the ratio of normal component of the rebound velocity to the approach normal velocity. The relation between $R_{n}$ and Schmidt rebounds was suggested by Peng (2000) through a series of laboratory rockfall tests, and expressed as:

$$
R_{n}=-0.110+0.00919 N_{1}+0.00392 N_{2}+0.00358 A
$$

where, $\mathrm{N}_{1} / \mathrm{N}_{2}$ are Schmidt numbers of rock slab and rock blocks and $\mathrm{A}$ is the angle of the slope. This regression was obtained from the data using various 23 different rock types of igneous, metamorphic and sedimentary rocks ranging from hard rocks to soft rocks. Based on the assumption that the 
material of the study area is categorized in the sedimentary rocks, the $\mathrm{R}_{\mathrm{n}}$ value was obtained by the empirical equation (Eq. 1) as shown in Table 1.

Unconfined compressive strengths (UCS) were also calculated using relations of the Schmidt hammer rebound values with uniaxial compressive strength suggested by Katz et al. (2000) (Eq. 2), where x is Schmidt rebounds. The unconfined strengths of the rocks are presented in Table 1.

$$
\operatorname{UCS}(\mathrm{Mpa})=2.208 e^{0.067 x}
$$

To estimate the friction angle of rock surface, a standard method of joint roughness coefficient (JRC) determination was performed using a profile gauge $(\mathrm{L}=25 \mathrm{~cm})$. JRC values, which vary from 0 to 20 , are obtained through the comparison of the measured joint surface geometry with the one presented in the Barton's standard profile chart (Barton and Choubey, 1977). The measurements were carried out between targets on a joint surface where the manual measurement was possible (Fig. 2). The coordinates of the measured profiles were digitized using AutoCAD program and the JRC values were estimated using a roughness parameter $Z_{2}$, which show strong relations with JRC values. The discrete form and the regression equation suggested by Tse and Cruden (1979) are shown in Eq. (3) and (4).

$$
\begin{aligned}
& Z_{2}=\left[\frac{1}{M\left(D_{x}\right)^{2}} \sum_{i=1}^{M}\left(y_{i+1}-y_{i}\right)^{2}\right]^{1 / 2} \\
& J R C=32.2+32.47 \log Z_{2}
\end{aligned}
$$

where $\mathrm{M}$ is the number of intervals, $\mathrm{D}_{\mathrm{x}}$ is a constant distance lag and the sum of the squares in adjacent $y$-coordinates is divided by the product of the number of intervals. The estimated JRC values are ranged from 11.1 to 14.3 .

\subsection{Rockfall experiments}

Rockfall experiments were carried out on a cut slope of the site (Fig 1). A total of 10 rocks, which were collected from the site, were manually thrown from the top position the slope. Horizontal and vertical falling distances from the toe of the slope were measured and the motion of falling rocks was recorded by a HD handy video recorder with an operating speed of $30 \mathrm{fps}$, which was positioned in front of the slope (Fig 1). The analysis of video recordings allowed for determination of the numbers 
of clear collisions and calculation of the arrival time of falling bodies. The analyses were focused on the recognition of trajectory directions, number of bounces and arrival times based on the observation. The shape of rock directly affects the rockfall trajectory. Leine et al., (2013) presented the influence of rock shapes on the rolling behavior of bodies introducing the 3D rockfall module 'RAMMS'. In the simulation, an arbitrary polyhedron block model was used as a falling body based on a high resolution digital elevation model. To describe the rock shapes of the collected rocks of this research project, a three dimensional shape index $(\gamma)$ developed by Wang et al., (2003) was used. The index which was the ratio of block volumes to the sphere volumes with a diameter equal to the maximum block size, could be estimated by Eq. (5). The rock block shapes were then classified into five categories according to the index. Examples of the collected rocks are shown in Figure 3.

$$
\gamma=\frac{6 \cdot V}{\pi \cdot l_{\max }^{3}}
$$

where, $\gamma=3 \mathrm{D}$ rock shape index, $\mathrm{V}=$ volume of a block, $1_{\max }=$ the maximum distance between two vertex points on the block (Fig. 3). The collected rock blocks were labeled as 'Block' or 'Cube' shapes as shown in Table 2.

\subsection{Behavior of rockfall}

General modes of motion of rocks during their descent on slopes are composed of free falling, rolling and bouncing phases based on slope gradients. In this rockfall test, the motions created various collision times through rockfall trajectories. It was observed from each rockfall test that the orientation of the joint sets at the impact points on the slope affected the trajectories of rockfalls. The lateral dispersion ratio $\left(D_{r}\right)$ is a proportion of the lateral distance $\left(D_{H}\right)$ of the rockfall paths from the center line as seen looking at the face of the slope to the length of the slope (L) as shown in Eq.(6). This definition of $D_{r}$ is similar to the concept presented by Azzoni and Freitas (1995) and is schematically shown in Figure 4.

$$
D_{r}=\frac{D_{H}}{L} \times 100(\%)
$$

In the field tests, the dispersion ratios $\left(\mathrm{D}_{\mathrm{r}}\right)$ of rockfalls were in the range of 5 to $50 \%$, which was much larger than the general dispersion ratio $(<20 \%)$ suggested by Azzoni and Freitas (1995). This large percentage of dispersion can be explained by the orientation of dominant joint sets dipping to a 
northeastern direction influencing the rockfall paths. Thus, the final positions of falling rocks were located at the left side from the center line including the falling point ranging from 0.6 to 6.3 meters as described in Table 3. It was observed from the field tests that the collision numbers through the rockfall trajectories directly correlated with the modes of rockfall. Less impact numbers such as 2 or 3 showed bigger jumping heights after collision with extruded rock surfaces. In contrast, sliding and rolling movement were predominant when the rock path showed more than 5 impacts.

Rock shape was also a major factor influencing the direction of trajectory of falling rocks. Figure 5 indicate the relationships between the rock shapes and the rockfall behavior. Even though the coefficients of determination, $\mathrm{R}_{2}$, are relatively low, it can be said that the obtained linear regressions obviously indicate downward or upward trends according to the rock shape indices. Figure 5 (a) shows distances of falling rocks from the toe according to their shape indices. As rock shape index increased, the distances of rockfall rose. Similarly, The rocks categorized as cube shape $(\gamma=0.23 \sim 0.37)$ created higher lateral dispersion ratio of trajectories ranging from 31 to $51 \%$, than the block shaped rocks $(\gamma=$ $0.10 \sim 0.21$ ) (Fig. 5(c)). The rockfall mode was also associated with rock shape index. It was also observed that sliding and rolling modes are predominant when the rock shape indices were relatively less (Fig. 5 (b)).

\subsection{Slope topography}

A geo-referenced 3D surface model was derived from the photogrammetry field survey. A single lens reflex digital camera (Nikon D7000) with a $24 \mathrm{~mm}$ focal length lens was employed to capture images of the rock slope. The pictures were taken in the distance of 30 meters from the slope to create the entire slope surface model. The computer program 'Sirovision' (CSIRO, 2005) was then used to build a 3D model and to analyse joint information. This computer code produced a high resolution 3D slope surface model $\left(1,620\right.$ pixels $\left./ \mathrm{m}^{2}\right)$ for the slope of the rockfall tests. Using more than 1,000 joint orientation data generated from the 3D model, the orientations of joint sets were analyzed. Computer code 'DIPS 6.0 (Rocscience)' which is designed for the stereonet plots based on geological data was used to define sets of the joint groups using mapping data obtained from the 3D model as presented in Figure 6.

The slope gradient within the study slope varied between $50^{\circ}$ and $60^{\circ}$. Ranges of dip and dip directions and joint spacing of the four prominent joint groups are presented in Table 4. Spacing of each joint set was obtained by measuring distances between joints on the 3D model to identify block 
shapes on the slope. As the dip direction of joint set 1 (J1) and joint set 2 (J2) face to the dip direction of the slope, it was expected that dip direction of the two prominent joints sets affect the directions of rock fall paths.

As rockfall events can be initiated by the detachment of rock fragments from their existing locations, characterizing the shape of distributed blocks on the slope surface can provide probable shapes of falling rock. Using the information of four joint sets, probable block shapes of the study slope were characterized by Eq.(7). To identify the rock shapes, block volumes were estimated using joint spacing and their orientations. Assuming that the main joint sets were persistent, in the cases that three or more joint sets are present, the block volume can be calculated using Eq.(7) proposed by Cai et al. (2004),

$$
V_{b}=\frac{s_{1} s_{2} s_{3}}{\sin \gamma_{1} \sin \gamma_{2} \sin \gamma_{3}}
$$

where, $\mathrm{s}_{1}, \mathrm{~s}_{2}, \mathrm{~s}_{3}=$ spacing between discontinuity sets; $\gamma_{1}, \gamma_{2}, \gamma_{3}=$ angles between discontinuity sets.

For practical purposes, this equation can be used to determine block sizes regarding the intersection angles between joint sets. In combination with four joint sets, using the average value of the joint orientation and distance data obtained from the 3D surface model, block volumes were analyzed as summarized in Table 4. Based on this procedure, it was found that the estimated block sizes ranged from 0.04 to $6.45 \mathrm{~m}^{3}$ and the block shapes were categorized as 'Sphere', 'Cube' or 'Block' shapes by the three dimensional shape index $(\gamma)$.

\section{Rockfall simulation}

In this study, 3D and 2D rockfall simulations were performed and the 3D simulations were focused on evaluation of probable rockfall trajectories in accordance with the topography of the slope and back calculation of the coefficient of restitution values based on rockfall arrival times. The $2 \mathrm{D}$ simulation was used to analyze the energy, bounce and the location of the falling rocks using the analysis section obtained from $3 \mathrm{D}$ simulation and to back calculate the tangential coefficient of restitution. In the simulations two software programs were used and detailed information are shown in Table 5.

\subsection{D simulation}


The 'Trajec3D' software (Basson, 2012) was used for the 3D simulation. This program estimates rockfall paths using realistic slope topographies that can be created from remote survey techniques, such as photogrammetry and LIDAR. 3D coordinates of the georeferenced 3D surface model generated from 'Sirovision (CSIRO, 2005)' were imported to the program 'Trajec3D' to create the slope surface model. The coefficient of restitution (COR) in the program represents the ratio of velocities before and after the rockfall impact as indicated in Eq. (8),

$$
C O R=\frac{v}{V}
$$

where $v$ : the velocity of the fall body after impact, $\mathrm{V}$ : the velocity of the fall body before impact. ' $\mathrm{COR}=1$ ' shows that the impact is perfectly elastic so there is no loss of energy. ' $\mathrm{COR}=0$ ' indicates that the impact is perfectly plastic.

In this study of the examined slope, a number of simulations were performed to back calibrate the coefficient of restitution (COR) from rockfall simulations. The COR values used in this parametric study were ranged from 0.3 to 0.9 . The results of 'rock no. 2' in the field test were compared with the simulation results. In the simulations, cube shape was selected as a rockfall shape as classified using the rock shape index (Table 2).

The friction angle was calculated using Barton's empirical equation (Barton and Choubey, 1977). JRC values obtained from site measurement were used to estimate the friction angle. In Eq.(9), the basic friction angle $\left(\phi_{\mathrm{b}}\right)$ of $35^{\circ}$ was obtained from a series of tilt tests using flat surface samples. Results from Schmidt hammer tests were used to estimate the joint compressive strength (JCS). Using Eq.(10), the friction angle of joints considering JRC was estimated to be $30^{\circ}$.

$$
\phi_{r}=\left(\phi_{\mathrm{b}}-20^{\circ}\right)+20(\mathrm{r} / \mathrm{R})
$$

Where, $\phi_{\mathrm{b}}$ is basic friction angle estimated from tilt tests; $\mathrm{R}$ is Schmidt rebound on dry unweathered joint surface; $r$ is Schmidt rebound on wet joint surfaces.

$$
\phi=\phi_{\mathrm{r}}+\mathrm{JRC} \log _{10}\left(\frac{\mathrm{JCS}}{\sigma_{\mathrm{n}}}\right)
$$

where, $\phi_{\mathrm{r}}$ is residual friction angle of joints; JCS is joint wall compressive strength; $\sigma_{\mathrm{n}}$ is normal stress acting on the joint plane. The input parameters used in the parametric study are presented in Table 6 . 
As the three dimensional model simulated detailed slope geometry, the rock paths obtained from the 3D simulation were considerably varied with the positions of dropping points on the slope. However, it was also observed that the rockfall trajectory was controlled by the orientation of the joint at the starting point. At the same starting points of rockfalls with the field tests, most rockfall paths headed towards the left side (Northeast) due to the orientation of the joint of dropping positions. Dip and dip direction of the joint indicates $44^{\circ} / 60^{\circ}$ heading to northeast direction as shown in Figure 7 . Therefore, the orientation of the joint at the starting point had a strong influence on the lateral dispersion rate. Even though similar trajectories were obtained from the same starting point, in the $3 \mathrm{D}$ parametric simulations, the trials were repeated twenty times for each COR value in order to obtain reliable data.

In terms of comparison of collision numbers with different COR values, it was natural that the rock collision numbers were decreased when the COR increased from 0.3 to 0.9 . The range of COR in Trajec3D simulation was relatively higher than the results from the previous research performed by Graf et al., (2013). The range of restitution coefficients in his tests for hard rocks was from 0.003 to 0.644. In comparison, the range in this simulation was reasonably determined by considering trends of collision numbers with the results from the field tests. The number of collisions was varied from 3 to 5 with COR of 0.3 and then reduced to 2 or 3 times using the COR of 0.9 . As the COR indicates the characteristic of the elasticity of slope surfaces, the rockfall pattern tended to change from bounce to rolling with decreased COR values. However, the change of collision numbers does not show tangible differences with COR values between 0.5 and 0.9 (Fig. 8 (a)).

It is clear that the increasing of COR resulted in faster falling. The results showed that the average arrival time obtained from the data distribution was reduced from 2.8 to 2.2 seconds as demonstrated in Fig. 8 (b). Due to the data noise along the edge of the 3D model, the top and ground bench parts were not fully generated in the slope model. Therefore, the arrival times were measured at the time when the rocks arrived at the toe of the slope. Figure 8 (b) showed that the rockfall elapsed time in the $3 \mathrm{D}$ simulation can demonstrate clearer tendencies according to the change of COR than the number of collision. Figure 9 shows a simulated rockfall path comparing it with the observed rockfall event when the COR value was 0.5. Despite slight differences, the simulated collision numbers and the rockfall direction agreed well with those of the rockfall test.

\subsection{D simulation}


In $2 \mathrm{D}$ rockfall simulations, the analysis model was assisted by 3D rockfall simulation to derive predefined rockfall path. The commercial software RocFall (Rocscience, 2003) was used for the simulation and the program is based on a lumped mass approach with separate coefficients of normal and tangential restitutions. The coefficients of restitution used in the simulation are presented in Table 7. The normal coefficient of restitution $\left(\mathrm{R}_{\mathrm{n}}\right)$ was calculated by the relation between Schmidt rebounds and $R_{n}$ as mentioned in 2.1. To determine the tangential coefficient of restitution $\left(R_{t}\right)$, four different $R_{t}$ values were used for parametric analyses comparing the results of rock endpoints from the field data. The $2 \mathrm{D}$ analysis model defined by a section along a 3D rockfall trajectory is shown in Figure 4 . This section was obtained by irregular cutting along the $3 \mathrm{D}$ simulation trajectory using the computer code 'Sirovision'.

It is obvious from the result that the coefficient of tangential restitution controls the distance of rockfall endpoints from the slope. As shown in Figure 10, with the rise in $\mathrm{R}_{\mathrm{t}}$ values, the mean values of the endpoints, which indicate most probable runout distances in the statistical simulations, increased from $4.4 \mathrm{~m}$ to $8.6 \mathrm{~m}$. In comparison with the measured distances in the field, the data distribution also suggests that proper $\mathrm{R}_{\mathrm{t}}$ value can be determined between 0.7 and 0.8 .

\subsection{Discussion}

The results of the simulations show that there is a clear relation between the COR and rockfall elapsed times in the $3 \mathrm{D}$ simulations. In the $2 \mathrm{D}$ analysis, there is also a good relationship between $\mathrm{R}_{\mathrm{t}}$ and rock endpoints. By establishing the linear relationship between the parameters shown in Fig. 11, the coefficient of restitution (COR) and tangential restitution $\left(R_{t}\right)$ can be back calibrated. In the graphs, $\mathrm{ts} / \mathrm{tr}$ is the ratio of simulated elapsed time to measured elapsed time and Ds/Dr is the ratio of simulated rock endpoints to measured rockfall endpoints respectively.

The results of the back calibrated coefficients $\left(\mathrm{COR}=0.57, \mathrm{R}_{\mathrm{t}}=0.73\right)$ were used to simulate $2 \mathrm{D}$ and $3 \mathrm{D}$ rockfall events again. From the comparison between $2 \mathrm{D}$ and $3 \mathrm{D}$ analyses for similar trajectories, the plot in Figure 12 shows the total kinetic energy curves values. In the upper part of the slope, where the block started to travel in the beginning, the simulated kinematic energies by both the simulations showed a different trend. This can be simply explained by the RocFall starting with bouncing patterns, while rocks on Trajec3D were thrown by a rolling pattern. Nevertheless, it is worth pointing out that the kinetic energy of both the simulations created similar values which were $0.42 \mathrm{~kJ}$ and $0.33 \mathrm{~kJ}$ respectively at the slope toe position. 


\section{Conclusions}

Field rockfall tests and 3D and 2D rockfall simulations based on photogrammetric 3D models were performed to assess the coefficients of restitution for the slope material. The combination of the simple field tests and the photogrammetry survey, which reflects the practical slope material and the realistic slope surface simulating exposed joint orientation, provided reliable coefficients of restitutions of the studied slope.

The results from the field test showed that the shape of rocks had a significant influence on the falling paths. The falling rocks with high rock shape index $(\gamma)$ produced higher lateral dispersed distances. Also, the surface geometry especially in the source area, directly affected the direction of rockfall paths. The use of a photogrammetry model in 3D rockfall modeling was successful in providing rock joints information to evaluate the shape of falling rocks as well. The simulation with different restitution coefficients (COR) indicated that rockfall elapsed time is a suitable factor to calibrate COR values from $3 \mathrm{D}$ simulations. The results of $2 \mathrm{D}$ simulation using a pre-defined rockfall path derived from a 3D analysis demonstrated that rockfall end points were sensitively varied with the coefficient of tangential restitution $\left(\mathrm{R}_{\mathrm{t}}\right)$. Consequently, the results of $2 \mathrm{D}$ simulation using a pre-defined rockfall path with the calibrated $\mathrm{R}_{\mathrm{t}}$ value showed a good agreement with the $3 \mathrm{D}$ rockfall trajectories.

\section{Acknowledgements}

The authors would like to express their appreciation to Mr. George Poropat from CSIRO and Dr. Hongyu Qin in Griffith University for the valuable help with this research. In addition, the authors appreciate Concrib Pty Ltd for the support to perform the site experiments.

\section{References}

Agliardi F, Crosta GB (2003) High resolution three-dimensional numerical modelling of rockfalls. Int J Roc Mech Min Sci 40:455-471

Andrew R et al., (2012) CRSP-3D User's Manual Colorado rockfall simulation program. Technical report, FHWA-CFL/TD-12-007

Arikan F, Ulusay R, Aydin N (2007) Characterization of weathered acidic volcanic rocks and a weathering classification based on a rating system. Bull Eng Geol Env 66:415-430 
Asteriou P, Saroglou H, Tsiambaos G (2012) Geotechnical and kinematic parameters affecting the coefficients of restitution for rock fall analysis. Int J Roc Mech Min Sci 54:103-113

Azzoni A, La Barbera G, Zaninetti A (1995) Analysis and prediction of rockfalls using a mathematical model. Int J Rock Mech Min Sci Geomech Abstr 32: 709-724

Azzoni A, de Freitas MH (1995) Experimentally gained parameters, decisive for rock fall analysis. Rock Mech Rock Eng 28(2): 111-124

Barton N, Choubey V (1977) The Shear Strength of Rock Joints in Theory and Practice. Rock Mech $10: 1-54$

Basson FRP (2012) Rigid body dynamics for rock fall trajectory simulation. The 46th US Rock Mechanics / Geomechanics Symposium, ARMA 12-267

Buzzi O, Giacomini A, Spadari M (2012) Laboratory investigation on high values of restitution coefficients. Rock Mech Rock Eng 45(1): 35-43

Cai M, Kaiser PK, Uno H, Tasaka Y, Minami M (2004) Estimation of rock mass deformation modulus and strength of jointed hard rock masses using the GSI system. Int J Rock Mech Min Sci 41: 3-19

Chau KT, Wong RHC, Wu JJ (2002) Coefficient of restitution and rotation motions of rockfall impacts. Int J Roc Mech Min Sci 39: 69-77

Christen M, Kowalski J, Bartelt D (2010) RAMMS: Numerical simulation of dense snow avalanches in three-dimensional terrain. Cold Reg Sci Technol, 63: 1-14

CSIRO (2005) Field procedures for photogrammetric pit mapping. CSIRO Exploration \& Mining

Dorren LKA, Berger F, Putters US (2006) Real-size experiments and 3-D simulation of rockfall on forested and non-forested slopes. Nat. Hazards Earth Syst Sci, 6: 145-153

Giacomini A, Thoeni K, Lambert C (2012) Improved management of the rock fall hazard at the base of the highwalls. ACARP project report C19026

Giovanni G, Stefano M, Simone F, Nicola C (2014) Terrestrial laser scanner and geomechanical surveys for the rapid evaluation of rock fall susceptibility scenarios. Landslides, 11: 1-14, DOI 10.1007/s10346-012-0374-0

Graf CC, Peryoga T, McCartney G, Rees T (2013) Verification of Trajec3D for use in rockfall analysis at Newmont Boddington Gold. Proc. Slope Stability 2013, Brisbane: 1231-1241

Guzzetti F, Crosta G, Detti R, Agliardi F, (2002) STONE: a computer program for the threedimensional simulation of rock-falls. Computers and Geosciences, 28: 1079-1093

Haramy KY, Zhang R, Rock A (2013) CRSP-3D Application for remediating a rockfall at Yosemite national park. Proc. Geo-Congress ASCE: 592-603

Katz O, Reches Z, Roegiers J-C (2000) Evaluation of mechanical rock properties using a Schmidt Hammer. Int J Rock Mech Min Sci 37: 723-728 
Leine RI, Schweize A, Christen M, Glover J, Bartelt P, Gerber W (2013) Simulation of rockfall trajectories with consideration of rock shape. Multibody Syst Dyn, DOI 10.1007/s11044-013-9393-4 Peng B (2000) Rockfall trajectory analysis-Parameter determination and application. Thesis of Master of Science in Engineering Geology in the University of Canterbury

Pfeiffer TJ (1989) Rockfall hazard analysis using computer simulation of rockfalls. Engineering Report, Colorado school of Mines, ER-3614

Rocscience Inc. (2003) RocFall Version 4.0 - Statistical Analysis of Rockfalls, www.rocscience.com, Toronto, Ontario, Canada

Stevens W (1998) RocFall: A tool for probabilistic analysis, design of remedial measures and prediction of rockfalls . M.A.Sc Thesis, Department of Civil Engineering, University of Toronto, Ontario, Canada

Tse R, Cruden DM (1979) Estimating joint roughness coefficients. Int J Rock Mech Min Sci 16:303307

Wang LG, Yamashita S, Sugimoto F, Pan C, Tan G (2003) A methodology for predicting the in situ size and shape distribution of rock blocks. Rock Mech Rock Eng, 36 (2): 121-142

Willmott W (2010) Rocks and landscape of the Gold Coast hinterland. Geological society of Australia, Queensland division 


\section{List of Figures}

Fig. 1 Overview of the study area and rockfall test set up

Fig. 2 JRC measurement and roughness profiles

Fig. 3 Examples of rock shapes of collected rocks

Fig. 4 Description of lateral dispersion $\left(\mathrm{D}_{\mathrm{H}}\right)$ and extraction of 2D simulation section from 3D slope surface model

Fig. 5 Relationships between block shape index and rockfall distance (a), numbers of bouncing (b) and dispersion ratio (c)

Fig. 6 Identified joint sets using DIPS 6.0

Fig. 7 Rock fall trajectory on Trajec3D (a) and joint orientation (Sirovision) (b) at the starting point

Fig. 8 Relationships between a) numbers of collisions, b) arrival time and coefficient of restitution

Fig. 9 Comparison of a simulated rockfall trajectory with field test result (rock no. 2)

Fig. 10 Data distribution of rock endpoints from toe according to coefficient of tangential restitution (RocFall analysis)

Fig. 11 Determination of coefficient of restitutions by back calibration

Fig. 12 Comparison of kinetic energy distributions of RocFall (a) and Trajec3D (b) simulation 
Table 1 Results of Schmidt hammer tests

\begin{tabular}{c|l|l|l}
\hline Location & $\begin{array}{l}\text { Schmidt hammer } \\
\text { rebounds }\end{array}$ & $\begin{array}{l}\text { Unconfined compressive } \\
\text { strength (UCS, Mpa) }\end{array}$ & $\begin{array}{l}\text { Coefficient of normal } \\
\text { restitution }\left(\mathrm{R}_{\mathrm{n}}\right)\end{array}$ \\
\hline $\begin{array}{c}\text { Slope surface } \\
\text { Rock blocks }\end{array}$ & $36 \sim 46($ mean $: 40.2)$ & 37.7 & 0.58 \\
\hline
\end{tabular}

Table 2 Details of the rock blocks

\begin{tabular}{c|l|l|l|l||c|l|l|l|l}
\hline $\begin{array}{c}\text { Rock } \\
\text { No. }\end{array}$ & $\begin{array}{l}\text { Weight } \\
(\mathrm{kN})\end{array}$ & $\begin{array}{l}\text { Volume } \\
\left(\mathrm{V}, \mathrm{cm}^{3}\right)\end{array}$ & $\begin{array}{l}\text { Shape } \\
\text { index }\left(\gamma^{*}\right)\end{array}$ & $\begin{array}{l}\text { Shape } \\
\text { description }\end{array}$ & $\begin{array}{l}\text { Rock } \\
\text { No. }\end{array}$ & $\begin{array}{l}\text { Weight } \\
(\mathrm{kN})\end{array}$ & $\begin{array}{l}\text { Volume } \\
\left(\mathrm{V}, \mathrm{cm}^{3}\right)\end{array}$ & $\begin{array}{l}\text { Shape } \\
\text { index }\left(\gamma^{*}\right)\end{array}$ & $\begin{array}{l}\text { Shape } \\
\text { description }\end{array}$ \\
\hline 1 & 62.5 & 2,360 & 0.37 & Cube & 6 & 10.0 & 377 & 0.21 & Block \\
\hline 2 & 57.0 & 2,150 & 0.23 & Cube & 7 & 23.0 & 868 & 0.21 & Block \\
\hline 3 & 12.5 & 472 & 0.18 & Block & 8 & 22.5 & 849 & 0.20 & Block \\
\hline 4 & 22.5 & 849 & 0.26 & Cube & 9 & 19.5 & 736 & 0.15 & Block \\
\hline 5 & 25.5 & 962 & 0.10 & Block & 10 & 36.0 & 1358 & 0.32 & Cube \\
\hline
\end{tabular}

$* \gamma \leq 0.001$ : Bar, $0.001<\gamma \leq 0.077$ : Plate, $0.077<\gamma \leq 0.22$ : Block, $0.22<\gamma \leq 0.37$ : Cube, $0.37<\gamma$

$\leq 1.0$ : Sphere (Wang et al., 2003)

Table 3 Results of rockfall tests

\begin{tabular}{|c|c|c|c|c|c|c|c|c|c|c|}
\hline Event no. & 1 & 2 & 3 & 4 & 5 & 6 & 7 & 8 & 9 & 10 \\
\hline Measured distance (m) & & & & & & & & & & \\
\hline - Vertical $\left(D_{\mathrm{V}}\right)$ & 2.1 & 4.2 & 1.5 & 3.3 & 1.0 & 2.6 & 5.1 & 2.8 & 1.2 & 2.5 \\
\hline - Horizontal $\left(\mathrm{D}_{\mathrm{H}}\right)$ & 5.8 & 6.3 & 1.2 & 5.1 & 2.1 & 0.6 & 2.8 & 2.5 & 2.8 & 3.9 \\
\hline$-\sqrt{D_{V}^{2}+D_{H}^{2}}$ & 6.1 & 7.5 & 1.9 & 6.1 & 2.3 & 2.7 & 5.8 & 3.8 & 3.0 & 4.6 \\
\hline $\begin{array}{r}\text { Lateral dispersion ratio } \\
\left(\mathrm{D}_{\mathrm{H}} / \mathrm{L}, \%\right)\end{array}$ & 46.5 & 50.5 & 9.6 & 40.9 & 16.8 & 4.8 & 22.5 & 20.0 & 22.5 & 31.3 \\
\hline Number of collision & 3 & 2 & 2 & 3 & 6 & 5 & 2 & 3 & 8 & 4 \\
\hline Arrival time (sec) & 3.5 & 2.5 & 3.5 & 2.5 & 3.5 & 3.0 & 2.5 & 3.5 & 4.5 & 3.5 \\
\hline
\end{tabular}

Table 4 Results of block volume and shape estimation using 3D surface model

\begin{tabular}{l|l|l|l|l|l|l}
\hline Plane & $\begin{array}{l}\text { Dip } \\
\left({ }^{\circ}\right.\end{array}$ & $\begin{array}{l}\text { Dip direction } \\
\left({ }^{\circ}\right)\end{array}$ & $\begin{array}{l}\text { Joint spacing } \\
(\mathrm{m})\end{array}$ & $\begin{array}{l}\text { Block volume } \\
\left(\mathrm{V}, \mathrm{m}^{3}\right),\end{array}$ & $\begin{array}{l}\text { Shape index, } \\
\gamma\end{array}$ & $\begin{array}{l}\text { Shape } \\
\text { description }\end{array}$ \\
\hline Slope & $55 \pm 5$ & $20 \pm 10$ & - & $0.04 \sim 6.45$ & $0.08 \sim 0.82$ & $\begin{array}{l}\text { Sphere / } \\
\text { Cube / }\end{array}$ \\
J1 & $54 \pm 15$ & $34 \pm 14$ & $0.30 \sim 1.41$ & & & Block \\
J2 & $59 \pm 17$ & $320 \pm 20$ & $0.31 \sim 1.65$ & & & \\
J3 & $84 \pm 7$ & $173 \pm 13$ & $0.28 \sim 1.01$ & & & \\
J4 & $47 \pm 5$ & $162 \pm 17$ & $0.34 \sim 0.55$ & & & \\
\hline
\end{tabular}


Table 5 Computer codes for rockfall simulation

\begin{tabular}{|c|c|c|}
\hline Programs & Required data & Outcomes \\
\hline $\begin{array}{l}\text { Trajec3D (3D) } \\
\text { (Basson, 2012) }\end{array}$ & $\begin{array}{l}\text { 3D surface model } \\
\text { Rock shapes * } \\
\text { Source area of rockfall } \\
\text { Coefficients of restitution (COR) }\end{array}$ & $\begin{array}{l}\text { Rock fall trajectories } \\
\text { - numbers of collisions } \\
\text { - horizontal displacement } \\
\text { Rock arrival time } \\
\text { Kinematic energy envelope }\end{array}$ \\
\hline $\begin{array}{l}\text { RocFall (2D) } \\
\text { (Stevens, 1998) }\end{array}$ & $\begin{array}{l}\text { Rock fall trajectories } \\
\text { Initial velocity of rockfall } \\
\text { Coefficients of tangential restitution } \\
\text { Coefficients of normal restitution }\end{array}$ & $\begin{array}{l}\text { Rock fall trajectories (Vertical) } \\
\text { Rock travelling distances } \\
\text { Kinematic energy envelope }\end{array}$ \\
\hline
\end{tabular}

* Applicable fall body shapes: Sphere, Cube, Plate and irregular blocks

Table 6 Parameters in 3D rockfall simulation

\begin{tabular}{|c|c|c|c|}
\hline Parameters & Unit & Value & Reference \\
\hline Density of rock & $\mathrm{kN} / \mathrm{m}^{3}$ & 27 & ASTM D5030 \\
\hline Block shape & - & Cube & Block shape index $(\gamma)$ \\
\hline Block size (cube length) & $\mathrm{m}$ & 0.13 & Equivalent length based on volume \\
\hline Coefficient of restitution (COR) & - & $0.3,0.5,0.7,0.9$ & $\begin{array}{l}\text { Range from intermediate to hard } \\
\text { rock (Andrew et al., 2012) }\end{array}$ \\
\hline Friction angle & $\circ$ & 30 & Barton's empirical equation \\
\hline
\end{tabular}

Table 7 Parameters in RocFall (Rocscience) simulation

\begin{tabular}{l|l|l}
\hline Parameters & Value & Reference \\
\hline Coefficient of normal restitution $\left(\mathrm{R}_{\mathrm{n}}\right)$ & 0.58 & Schmidt hammer test \\
Coefficient of tangential restitution $\left(\mathrm{R}_{\mathrm{t}}\right)$ & $0.6,0.7,0.8,0.9$ & Rocscience Inc.,(2003) \\
Friction angle $\left(^{\circ}\right)$ & 30 & Barton's empirical equation \\
\hline
\end{tabular}




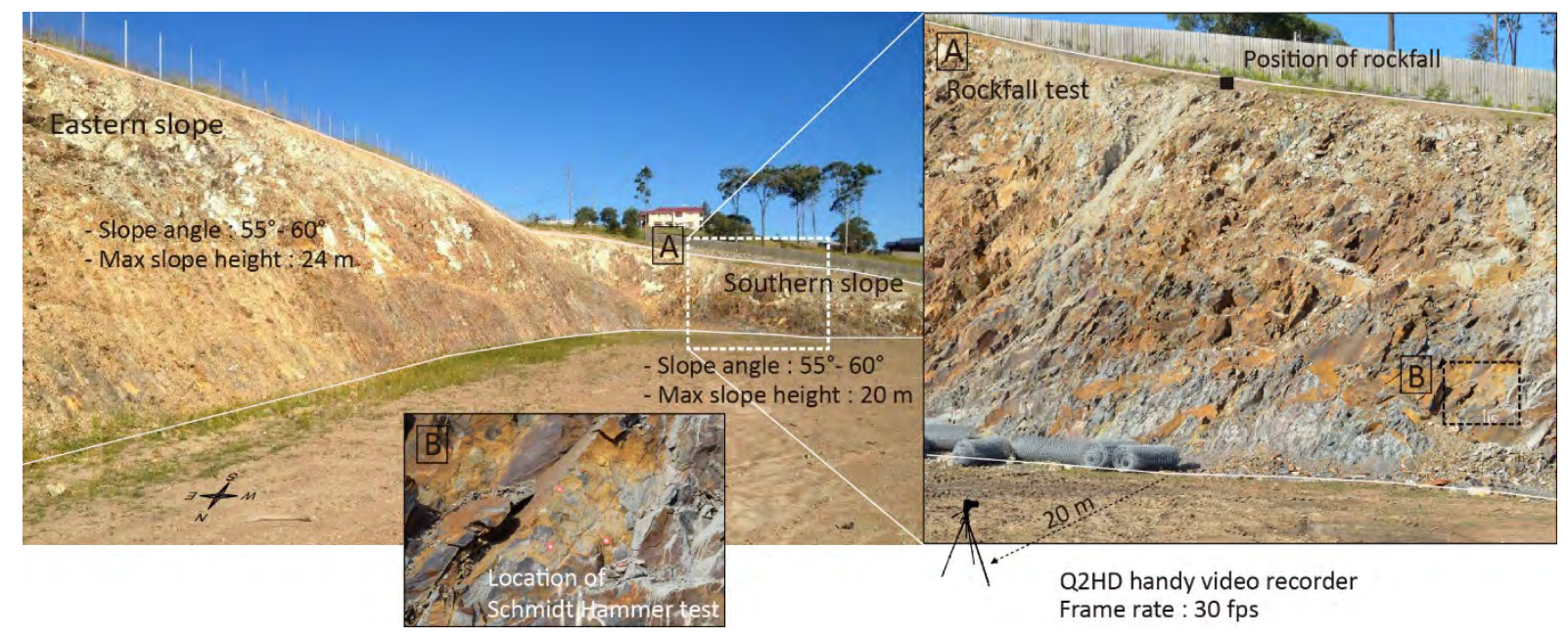

Fig. 1 Overview of the study area and rockfall test set up

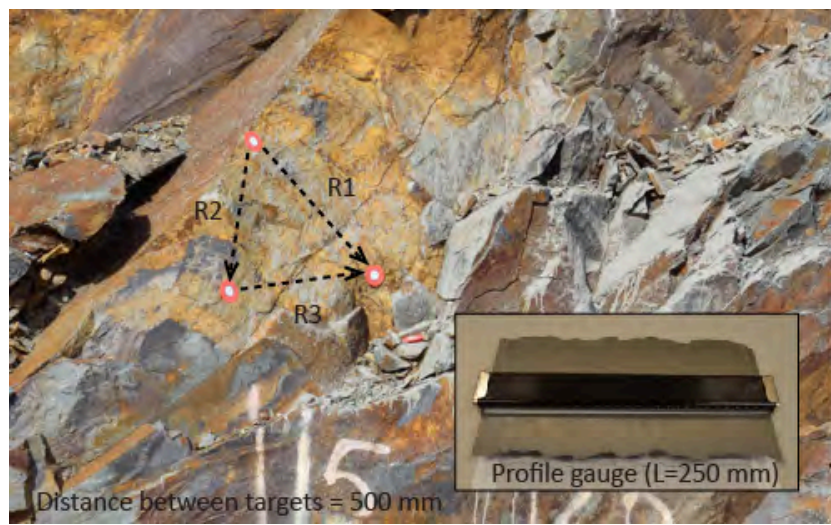

Fig. 2 JRC measurement and roughness profiles

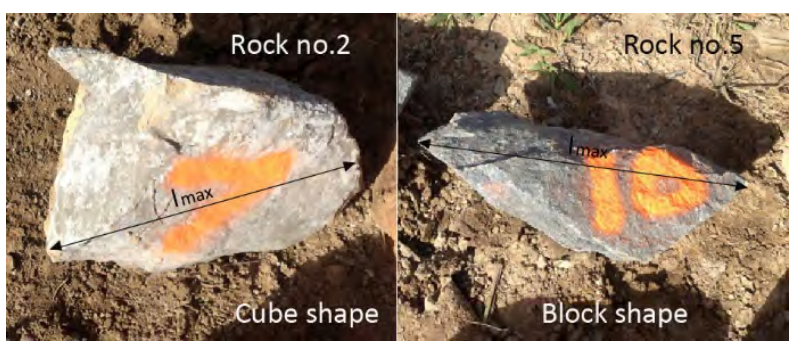

Fig. 3 Examples of rock shapes of collected rocks

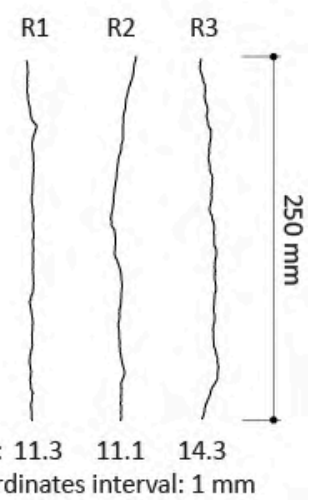

Coordinates interval: $1 \mathrm{~mm}$ 

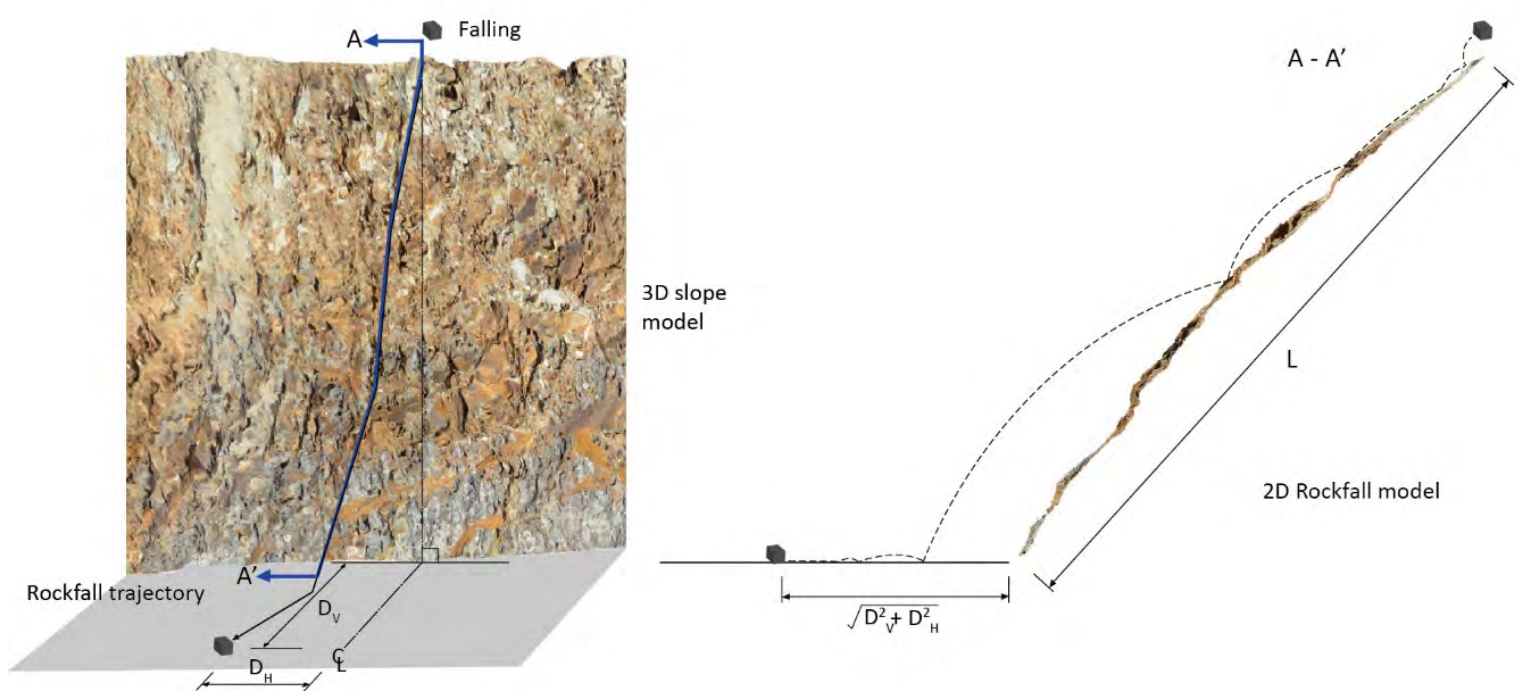

Fig. 4 Description of lateral dispersion $\left(\mathrm{D}_{\mathrm{H}}\right)$ and extraction of 2D simulation section from 3D slope surface model
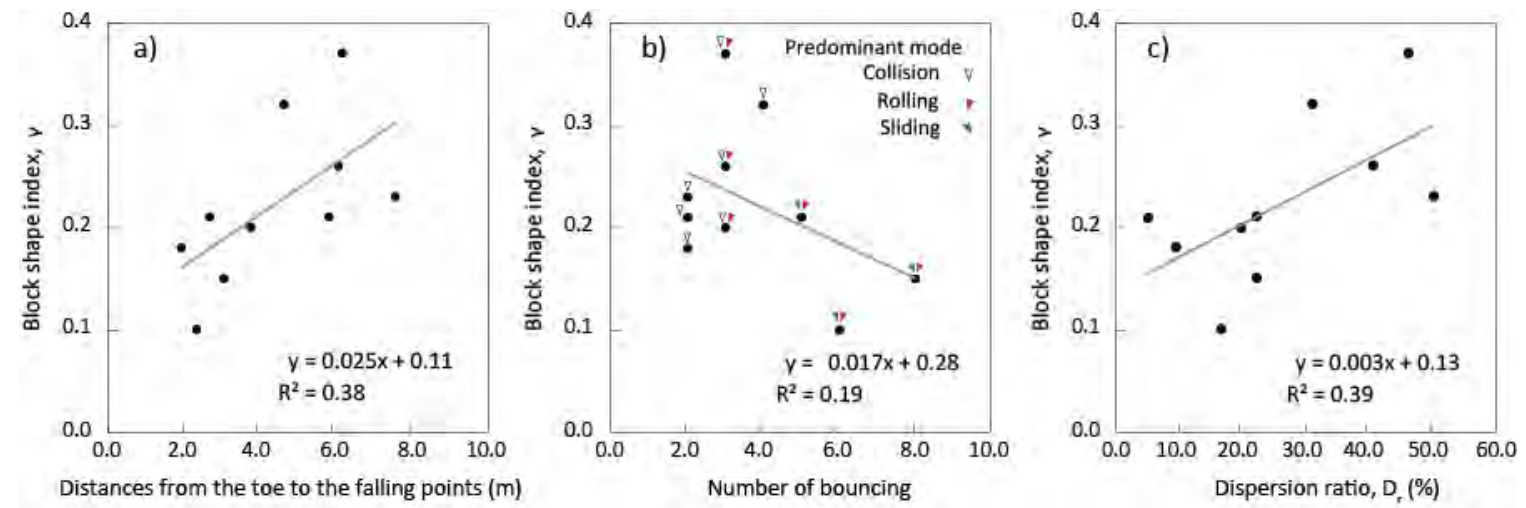

Fig. 5 Relationships between block shape index and rockfall distance (a), numbers of bouncing (b) and dispersion ratio (c) 


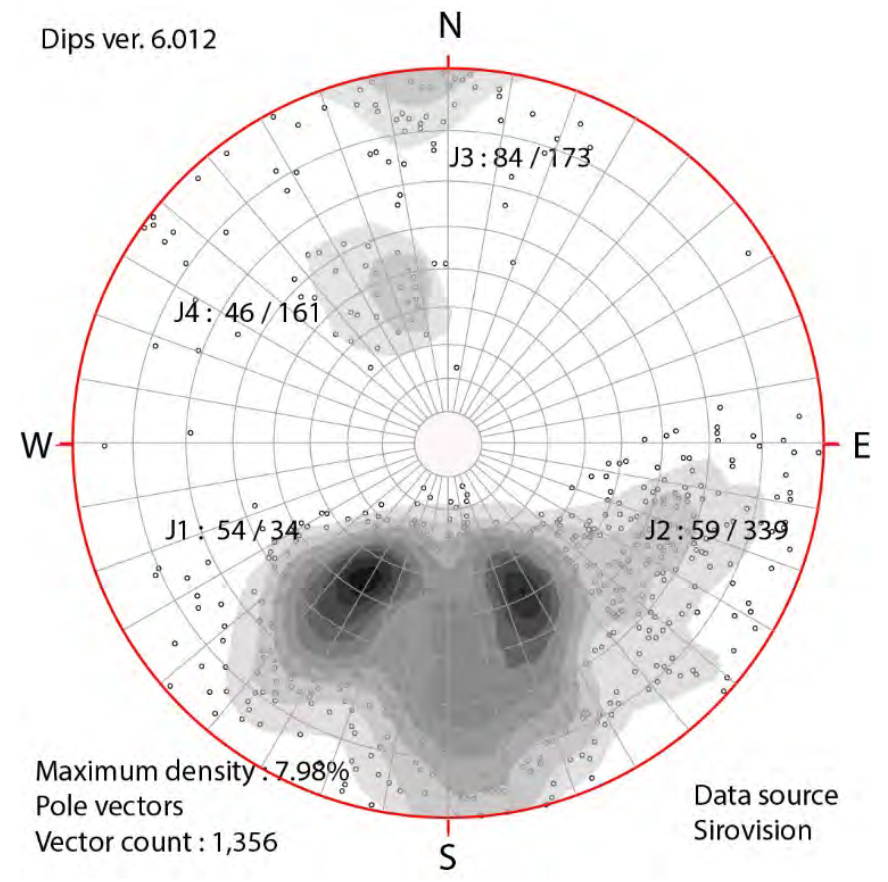

Fig. 6 Identified joint sets using DIPS 6.0

a)

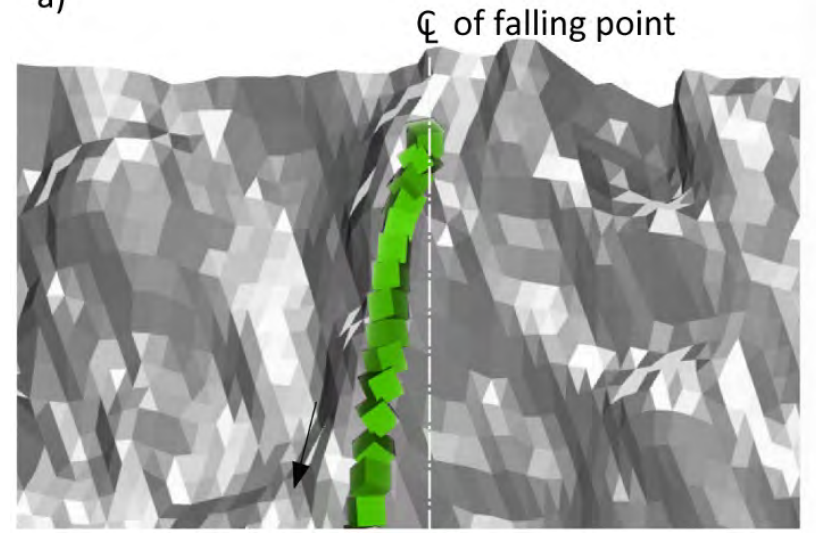

b)

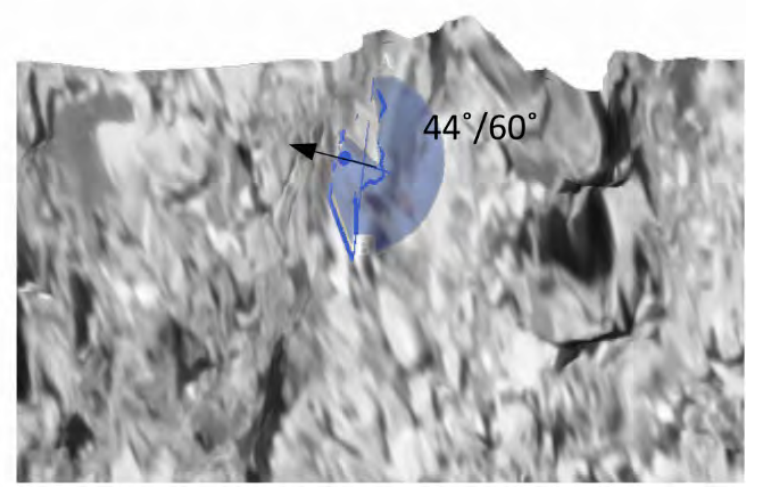

Fig. 7 Rock fall trajectory on Trajec3D (a) and joint orientation (Sirovision) (b) at the starting point 

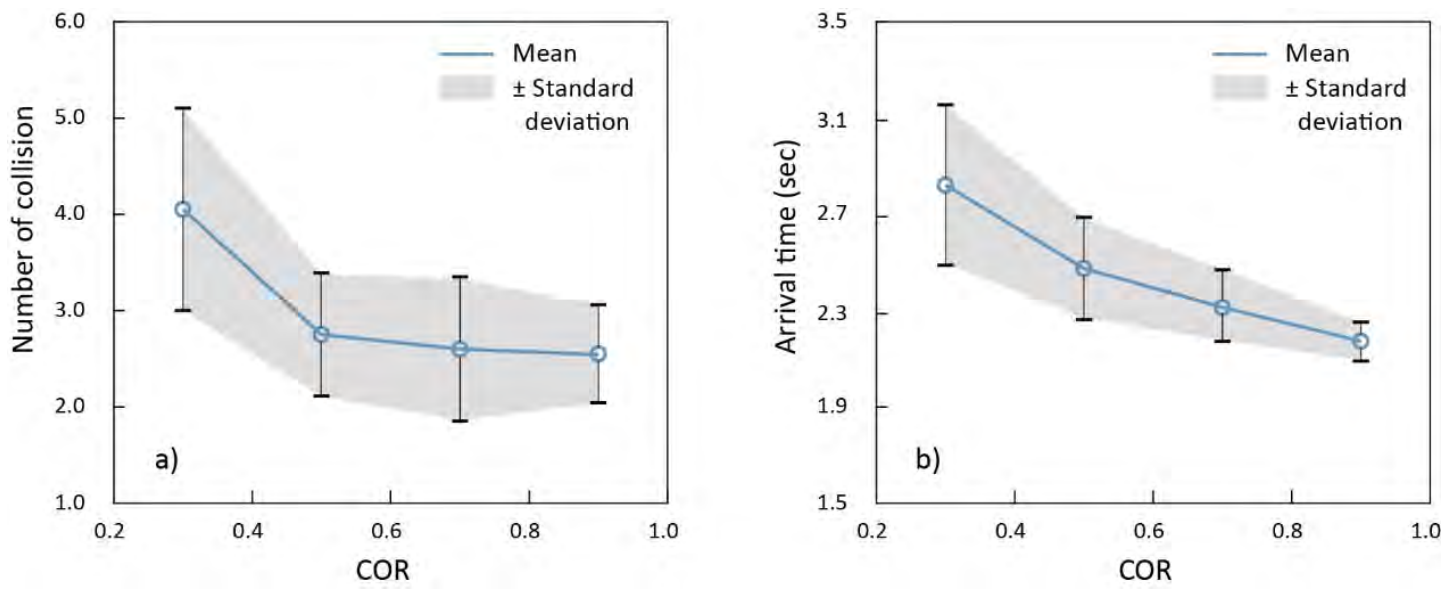

Fig. 8 Relationships between a) numbers of collisions, b) arrival time and coefficient of restitution

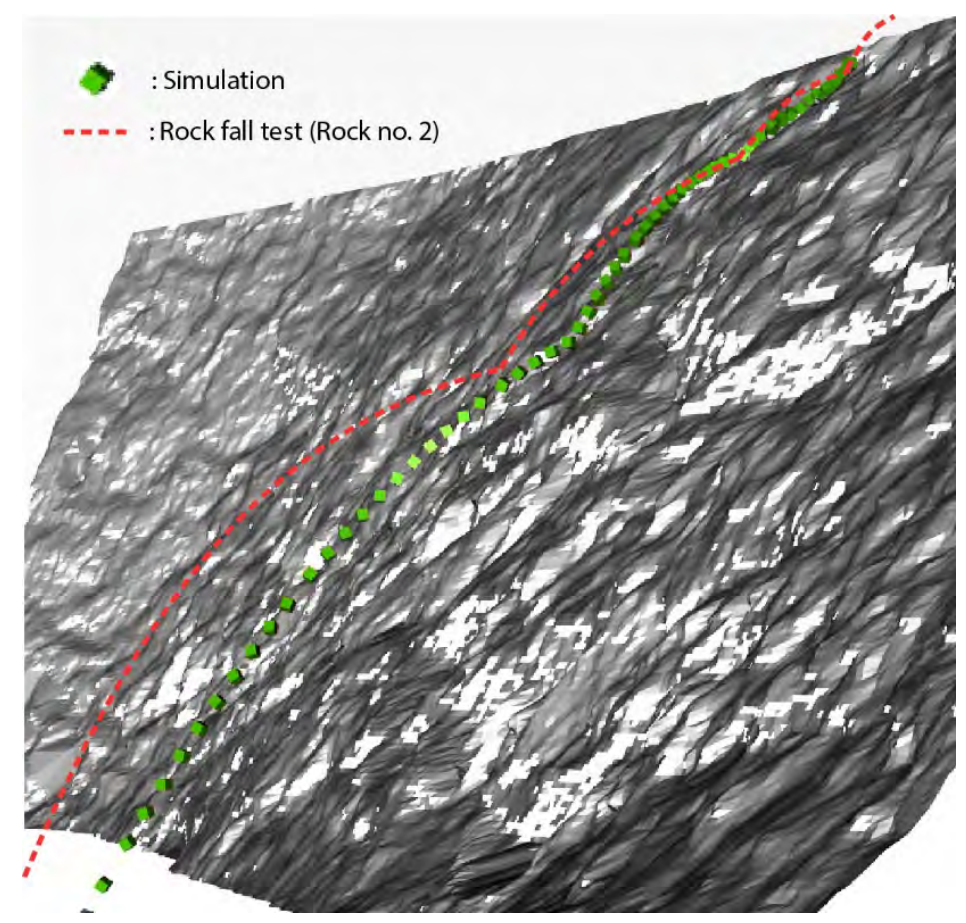

Fig. 9 Comparison of a simulated rockfall trajectory with field test result (rock no. 2) 

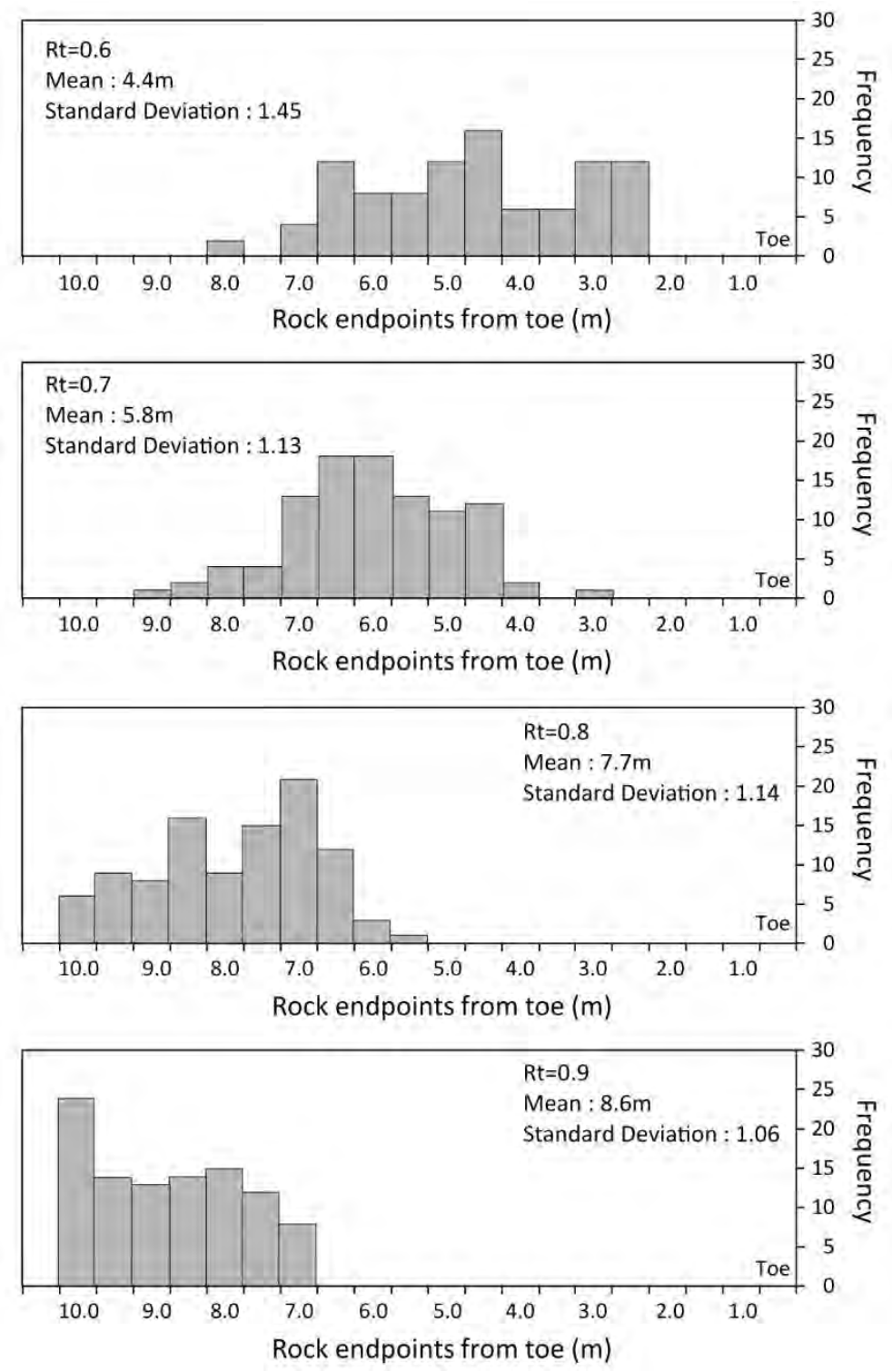

Fig. 10 Data distribution of rock endpoints from toe according to coefficient of tangential restitution (RocFall analysis) 

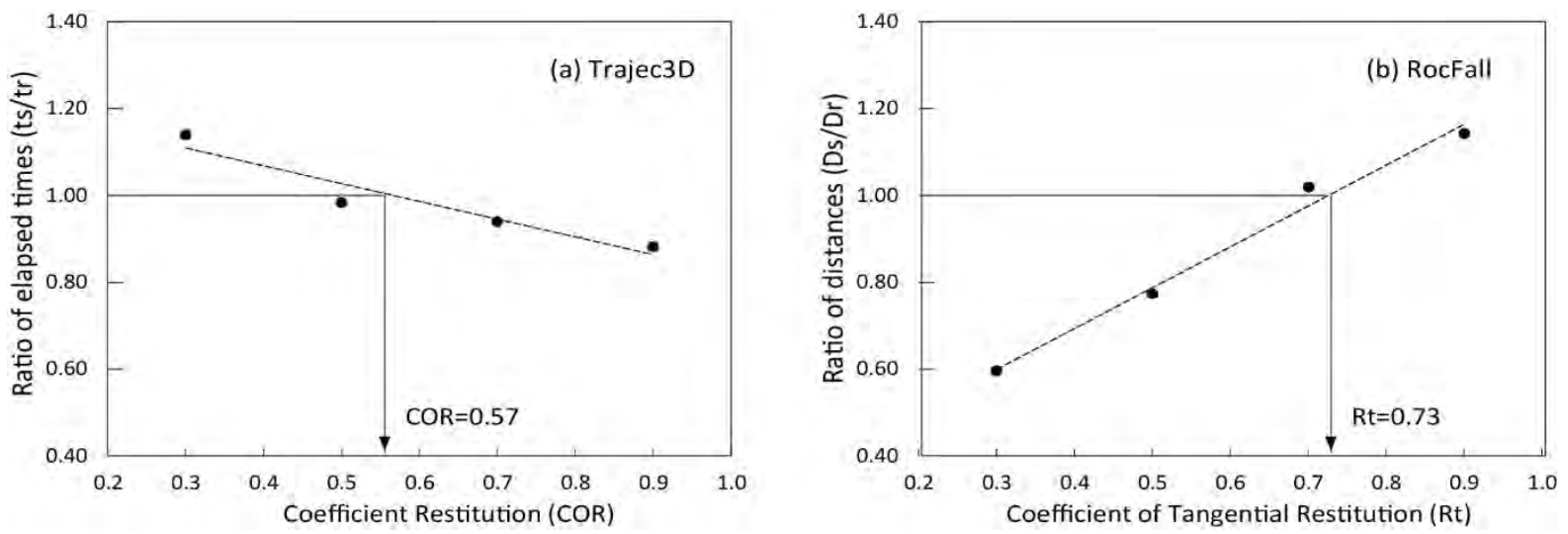

Fig. 11 Determination of coefficient of restitutions by back calibration
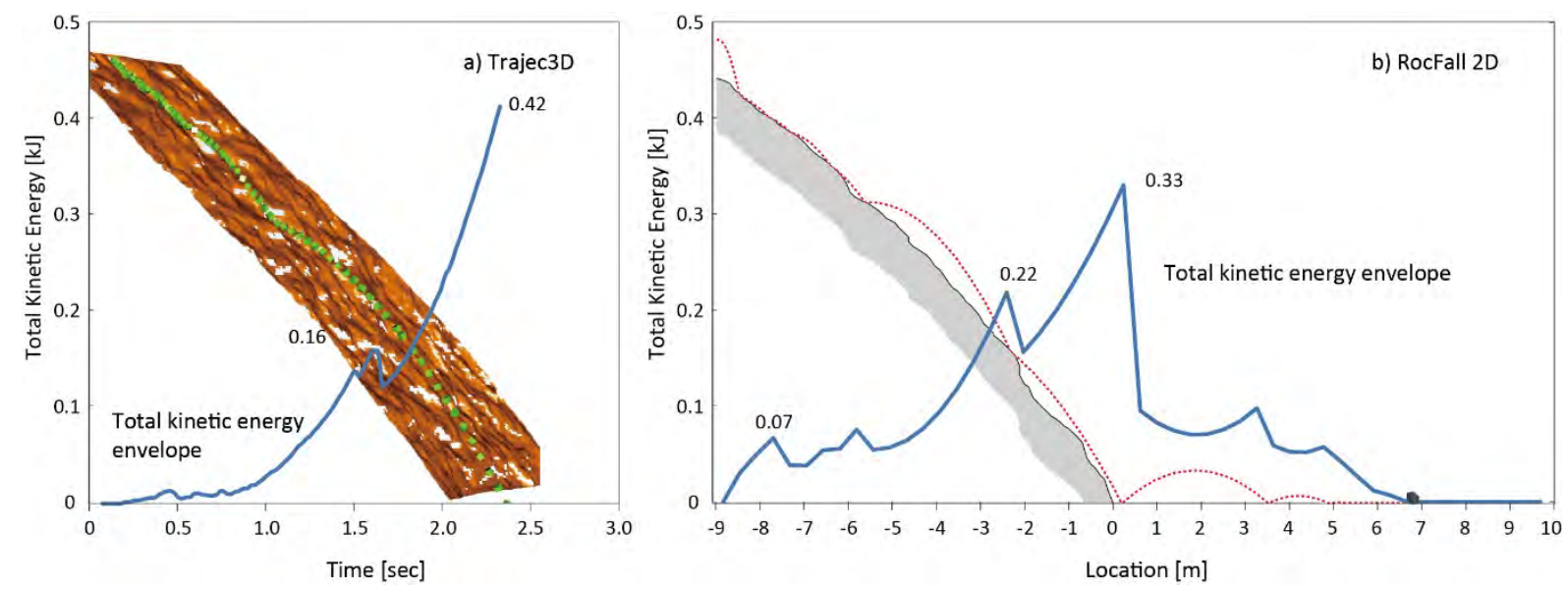

Fig. 12 Comparison of kinetic energy distributions of RocFall (a) and Trajec3D (b) simulation 